\title{
Clinical Research: Auditory Stimulation in the Disorders of Consciousness
}

\author{
Jiajie Zhu't, Yifan Yan ${ }^{1+}$, Wei Zhou't, Yajun Lin', Zheying Shen ${ }^{1}$, Xuanting Mou', \\ Yan Ren ${ }^{1}$, Xiaohua Hu${ }^{2 *}$ and Haibo $\mathrm{Di}^{1 *}$ \\ ${ }^{1}$ International Vegetative State and Consciousness Science Institute, Hangzhou Normal University, Hangzhou, China, \\ ${ }^{2}$ Department of Rehabilitation, Hangzhou Wujing Hospital, Hangzhou, China
}

OPEN ACCESS

Edited by:

Camillo Porcaro,

Istituto di Scienze e Tecnologie della

Cognizione (ISTC), Italy

Reviewed by:

Xiaoyu Xia,

The Military General Hospital

of Beijing PLA, China

Francisco Gomez,

University of Liège, Belgium

Antonino Naro,

Centro Neurolesi Bonino Pulejo

(IRCCS), Italy

${ }^{*}$ Correspondence:

Haibo Di

dihaibo19@aliyun.com

Xiaohua $\mathrm{Hu}$

104216321@qq.com

${ }^{t}$ These authors have contributed equally to this work as co-first authors

Specialty section:

This article was submitted to Brain Imaging and Stimulation, a section of the journal

Frontiers in Human Neuroscience

Received: 30 January 2019 Accepted: 03 September 2019

Published: 26 September 2019

Citation:

Zhu J, Yan Y, Zhou W, Lin Y,

Shen Z, Mou X, Ren Y, Hu X and Di H

(2019) Clinical Research: Auditory

Stimulation in the Disorders

of Consciousness.

Front. Hum. Neurosci. 13:324.

doi: 10.3389/fnhum.2019.00324
Due to the complex situation of disorder of consciousness (DOC) patients, the assessment of conscious states of these patients has become a huge challenge for a long time (Laureys et al., 2010). At present, the main clinical diagnostic method to assess the conscious state of a DOC patient is the use of a relevant behavior scale like the Coma Recovery Scale-Revised (CRS-R). In this article, we will focus on auditory stimulation and select some representative auditory stimulus, like calling names and music stimulation, to discuss the function and application of the auditory stimulus in patients with DOC and provide guidance for future research.

Keywords: disorder of consciousness, auditory stimulation, minimally consciousness state, music, name

\section{INTRODUCTION}

Disorders of consciousness (DOC) are commonly caused by severe brain damage, and include minimally conscious state (MCS) and unresponsive wakefulness syndrome (UWS)(Laureys et al., 2010). Patients in DOC show less awareness of the surroundings and can remain in the same stage for months or years but the difference among these patients can be found in the levels of awareness and wakefulness. While there is arousal but no awareness in UWS, MCS shows fluctuating but reproducible signs of consciousness but an absence of reliable communication (Giacino et al., 2002). Plenty of studies have been carried out and several methods have been developed to differentiate the different states, like The Sensory Modality Assessment and Rehabilitation Technique (SMART) (Gill-Thwaites, 1997), The Wessex Head Injury Matrix (WHIM) (Shiel et al., 2000), the Sensory Tool to Assess Responsiveness (STAR) (Stokes et al., 2018), the Glasgow Coma Scale (GCS) (Teasdale and Jennett, 1972), the COMA/Near Coma Scale (CNC) (Rappaport et al., 2006), the Glasgow Outcome Scale (GOS) (Teasdale and Jennett, 1972), and the Coma Recovery Scale-Revised (CRS-R).

The CRS-R is a widely used behavioral assessment scale for DOC recommended by a review of the American Congress of Rehabilitation Medicine with 6 subscales designed to assess visual, auditory, motor, and verbal, communication and arousal (American Congress of Rehabilitation Medicine et al., 2010; Gerrard et al., 2014). The CRS-R has become a standardized measure of consciousness that has been widely used for diagnostic assessment in studies involving persons with DOC (Gerrard et al., 2014).

The primary auditory cortex is made up of horizontal gyrus and superior temporal gyrus, and the afferent fibers of the auditory nerve form the lateral thalamus after crossing the 
same side of the brain stem, then the lateral thalamus fibers reach the medial geniculate body, and the latter emits fibers to form auditory radiation ending in the primary cortex. Middle ear, inner ear, or auditory nerve damage may lead to hearing disorders (Allen et al., 2013). Auditory stimulation is a kind of stimulation that can enrich the environment to improve arousal and awareness state in patients with DOCs and is widely used. Clinical studies believe that the generation of consciousness is the result of the joint action of multiple brain networks. The auditory cortex is an important part of some of the brain networks (Default mode network) (Cook et al., 2019). Clinically, the activation of the auditory cortex is compared with the patient's state of consciousness and it is concluded that the retention of the auditory cortex may be an indicator of the retention of consciousness (Heine et al., 2015). Tests based on auditory stimulation like auditory startle and localization to sound in CRSR (American Congress of Rehabilitation Medicine et al., 2010) play an important role and more auditory stimulations have been used on other subjects (Teasdale and Jennett, 1972; GillThwaites, 1997; Shiel et al., 2000; Stokes et al., 2018). Auditory stimulation is also effective in the recovery of consciousness, and a recent study focusing on the impact of sensory stimulation programs (SSP) in the recovery of DOC highlighted that SSP may not be sufficient to restore consciousness but it may lead to improved behavioral responsiveness in MCS patients (Cheng et al., 2018).

\section{AUDITORY STIMULUS IN DOC FOR DIAGNOSIS}

Though auditory stimulation plays an important role, patient's response to stimuli like music, bells, and calling names can differ, therefore researchers tried to select the most sensitive stimulation for diagnosis between auditory stimulus and auditory and other sensory stimulation, while behavioral indicators (sound fixation, CRS-R scores), brain neurophysiological indicators (fMRI, EEG, ERP), and other indicators like skin conductance level (SCL) were applied to evaluate the effect. Due to the diversity of assessment methods, the selection of methods is particularly important. Active paradigms can be used to compare patients and healthy controls, if they are activated in the related region in the active paradigm fMRI. Some patients with higher levels of consciousness were even able to answer simple yes or no questions by completing different tasks. Active paradigms are also helpful to recognize conscious patients who were misdiagnosed on the behavior scale, and couldn't answer the CRS-R but achieved positive results in the active paradigms fMRI (Naci and Owen, 2013). A study aiming to find the difference in SCLs during music stimulus and odor stimulus showed that no obvious difference was observed between two conditions (Li et al., 2018), while other studies with the same type of stimulation but employing different dependent measures like behavior change came out with totally different results (Heine et al., 2017) (Please see Table 1, the reference has been summarized in it). In consideration of the outcome of these studies, the problem may not be the choice of stimulus but the SCL is not an appropriate indicator for the study, which highlighted that selecting a suitable measure is the key point in DOC researches and its role in diagnosis of DOC.

Besides measures, choosing a reliable stimulus is important. From the studies we gathered, it appears clear that compared to other stimulation, auditory stimulation has a potential role in improving state of consciousness and it's worth noting that calling a patient's name might be the most effective choice followed by preferred music. A comparison between calling a patient's name and other auditory stimulations varying from white noise to tones has been carried out through different dependent measures in recent years (Cheng et al., 2013; Verger et al., 2014; Heine et al., 2015; Li et al., 2018; Wu et al., 2018), and the results seemed to confirm the conclusion that calling the Subject's Own Name (SON) may be the most effective auditory stimulation. An EEG study ran by Kempny et al. (2018) using SON and others' name on 16 patients ( 5 UWS; $11 \mathrm{MCS}$ ) indicated that there seemed to be no significant difference between DOC patients' response to SON and others' name at the group level, but 4 of 15 patients showed significantly different responses between hearing their own name and others' names at a single subject and two of these patients had similar responses as controls (Kempny et al., 2018), while another fMRI study applying the patient's mother's voice and a stranger's voice to read the same story reported by Bekinschtein et al. (2004) showed that, compared to the unfamiliar voice, the brain activation is stronger under a familiar sound condition. The patient's mother's voice activates the extended amygdala, an emotionally related structure, and a directly connected area such as the insula, perhaps acting jointly as limbic integration cortex.

Combining this result with other studies' (Bekinschtein et al., 2004), it's safe to say a personal-relevant stimuli works better than a meaningless sound, but personal-relevant includes not only SON but also stimuli like preferred music or similar. Studies also showed that compared to meaningless sound or unlike music, the auditory network of DOCs seemed to have stronger functional connectivity while hearing one's preferred music than the control condition, and especially in the left precentral gyrus and the left dorsolateral prefrontal cortex (Heine et al., 2015), functional connectivity of the external network was also enhanced during the music palying in the temporo-parietal junction (Heine et al., 2015). The same conclusion was reached by another CRS-R study (Verger et al., 2014).

For its unique role as a personal-relevant stimulus and the lack of sensitive assessment in auditory block in CRS-R, "Music therapy assessment tool for awareness in disorders of consciousness" (MATADOC) has been developed as a more detailed auditory assessment tool (Magee et al., 2014) based on three subscales, the "Principal Subscale", the "Musical Parameter and Behavioral Response Type" and the third subscale, "Clinical Information to Inform Goal Setting and Clinical Care" (Magee et al., 2014). Only the "Principal Subscale" achieved diagnosis and the other two subscales are designed to guide treatment (Magee et al., 2016). MATADOC could serve as a better way for the pediatric population suffering from DOC given the lack of language and motor functions (Magee et al., 2015).

The selection of the stimulus is crucial for an accurate evaluation of the state of patients with disorders of consciousness 
TABLE 1 | A review of the literature related to this article.

\begin{tabular}{|c|c|c|c|c|c|}
\hline Objectives & References & Methods & Stimulus & Subjects & Main outcome \\
\hline \multirow[t]{14}{*}{ Diagnosis } & Li et al., 2018 & EEG & Music, call-names, habit stimulation & $\begin{array}{l}9 \text { MCS; } 10 \\
\text { UWS }\end{array}$ & Call-name stimulation > habit > music stimulations. \\
\hline & Heine et al., 2017 & CRS-R & $\begin{array}{l}\text { Preferred or neutral auditory stimuli and odor } \\
\text { stimuli }\end{array}$ & 7 MCS; 6 UWS & Auditory stimuli > a olfactory stimuli \\
\hline & & & & & Preferred stimuli > neutral stimuli. \\
\hline & Verger et al., 2014 & CRS-R & Preferred music, a continuous sound & $\begin{array}{l}5 \text { MCS+; } \\
1 \text { MCS- }\end{array}$ & Preferred music > meaningless sound \\
\hline & Cheng et al., 2013. & Behavior & Patient's own name, ringing bells & $\begin{array}{l}39 \text { MCS; } 47 \\
\text { UWS }\end{array}$ & Own name > ringing bells \\
\hline & Wu et al., 2018. & EEG & Music, own names, white noise & 7 MCS; 7 UWS & Subject's own name $>$ music \\
\hline & & & & & Subject's own name $>$ white noise \\
\hline & & & & & White noise/music $>$ silence \\
\hline & & & & & $\begin{array}{l}\text { No obvious difference observed between white } \\
\text { noise and music. }\end{array}$ \\
\hline & $\begin{array}{l}\text { Bekinschtein et al., } \\
2004 .\end{array}$ & fMRI & Non-familiar voice, silence, mother's voice & Case report & Familiar voice > silence \\
\hline & & & & & Familiar voice > unfamiliar voice \\
\hline & Okumura et al., 2014. & fMRI & $\begin{array}{l}\text { Baseline sound stimulation; instrument sound } \\
\text { stimulation }\end{array}$ & $\begin{array}{l}5 \mathrm{VS} ; 2 \text { MCS; } \\
21 \text { healthy } \\
\text { controls }\end{array}$ & MCS > VS [bilateral superior temporal gyri (STG)] \\
\hline & Luaute et al., 2018. & $\mathrm{SCL}$ & $\begin{array}{l}\text { Preferred music, neutral sound, preferred } \\
\text { odors, and neutral odors. }\end{array}$ & $\begin{array}{l}7 \text { MCS; } 6 \\
\text { UWS; } 7 \text { healthy } \\
\text { controls }\end{array}$ & $\begin{array}{l}\text { No significant difference between conditions was } \\
\text { detected in patients. }\end{array}$ \\
\hline & Kempny et al., 2018 & ERP & Subject's own name and other's name & $\begin{array}{l}12 \mathrm{HC} ; 5 \mathrm{VS} ; \\
11 \mathrm{MCS}\end{array}$ & $\begin{array}{l}\text { Using this paradigm in } 4 \text { DOC patients we detected } \\
\text { a statistically significant difference in EEG response } \\
\text { to their own name versus other peoples' names. }\end{array}$ \\
\hline \multirow[t]{6}{*}{ Prognosis } & Di et al., 2007. & fMRI & Subject's own name & $\begin{array}{l}7 \text { VS; } 4 \text { MCS; } \\
12 \text { health }\end{array}$ & Adults and patients in an MCS. \\
\hline & Wang et al., 2015. & fMRI & Subject's own name & $\begin{array}{l}39 \text { MCS }(23 \\
\text { non-traumatic; } \\
16 \text { traumatic) }\end{array}$ & $\begin{array}{l}12 \text { out of } 16 \text { VS/UWS patients with higher level } \\
\text { activation recovered to MCS or EMCS, whereas } 17 \\
\text { out of } 23 \text { VS/UWS patients with no activation or } \\
\text { activation. }\end{array}$ \\
\hline & Fischer et al., 2008 & $\begin{array}{l}\text { A passive oddball } \\
\text { paradigm (SON) }\end{array}$ & Subject's own name & 50 coma & $\begin{array}{l}\text { Compared to MMN, P3 showed as large a } \\
\text { specificity for awakening. }\end{array}$ \\
\hline & Perrin et al., 2006. & ERP-P3 & Subject's own name & $\begin{array}{l}5 \text { VS; } 6 \text { MCS; } 4 \\
\text { LIS }\end{array}$ & $\begin{array}{l}\text { A P } 3 \text { component was observed in response to the } \\
\text { patient's name in LIS, in all MCS patients, and in } 3 \\
\text { of } 5 \text { patients in a VS. }\end{array}$ \\
\hline & Qin et al., 2008 & ERP-oddball; CRS-R & Subject's own name & 4 coma & N100 9/13 \\
\hline & $\begin{array}{l}\text { Qin et al., } 2008 \\
\text { Literature }\end{array}$ & $\begin{array}{l}\text { ERP-oddball; CRS-R } \\
\text { Methods }\end{array}$ & Subject's own name Stimulus & $7 \mathrm{VS}$ & $\mathrm{Nd} 7 / 13$ \\
\hline
\end{tabular}


TABLE 1 | Continued

\begin{tabular}{|c|c|c|c|c|c|}
\hline Objectives & References & Methods & Stimulus & Subjects & Main outcome \\
\hline & & & & $2 \mathrm{MCS}$ & MMN 1/13 \\
\hline & & & & & P300 4/13 \\
\hline & & & & & 2 MCS has Nd and N100, but no MMN and P300 \\
\hline & & & & Subjects & Main outcome \\
\hline & Berlad and Pratt, 1995 & $\begin{array}{l}\text { Active and passive oddball } \\
\text { 3-word paradigm }\end{array}$ & Subject's own name & 12 subjects & $\begin{array}{l}\text { P300 amplitude to the subject's name was larger } \\
\text { than to the irrelevant rare word in } 9 \text { of the } 10 \\
\text { subjects. }\end{array}$ \\
\hline & Heine et al., 2015 & fMRI & $\begin{array}{l}\text { Five musical excerpts selected from a } \\
\text { questionnaire }\end{array}$ & $\begin{array}{l}4 \text { MCS; } 3 \\
\text { UWS; } 8 \text { healthy } \\
\text { participants }\end{array}$ & $\begin{array}{l}\text { Music }>\text { control (left precentral gyrus and the left } \\
\text { dorsolateral prefrontal cortex) }\end{array}$ \\
\hline & Magee et al., 2014. & MATADOC; SMART & / & 21 patients & MATADOC = SMART (the principal subscale) \\
\hline & O'Kelly et al., 2013 & EEG; behavioral responses & $\begin{array}{l}\text { Preferred music; improvised music; } \\
\text { disliked music; white noise; silence }\end{array}$ & $\begin{array}{l}12 \text { VS; } 9 \text { MCS } \\
20 \text { healthy } \\
\text { controls }\end{array}$ & $\begin{array}{l}\text { Frontal midline theta in } 6 \mathrm{VS} \text { and } 4 \mathrm{MCS} \text { subjects, } \\
\text { and frontal alpha in } 3 \mathrm{VS} \text { and } 4 \mathrm{MCS} \text { subjects were } \\
\text { found during preferred music stimulation }\end{array}$ \\
\hline \multirow[t]{8}{*}{ Treatment } & Ribeiro et al., 2014. & $\begin{array}{l}\text { Vital signs; Facial } \\
\text { expressions }\end{array}$ & Musical stimuli; radio; CRM; RMNS & $26 \mathrm{VS}$ & Music stimuli > radio/CRM/RMNS \\
\hline & Raglio et al., 2014. & $\begin{array}{l}\text { Physiological parameters; } \\
\text { behavioral responses }\end{array}$ & Individual AMT & 4 MCS; 6 VS & After therapy $>$ before therapy \\
\hline & Steinhoff et al., 2015 & PET & Music Therapy (MT) & $4 \mathrm{VS}$ & $\begin{array}{l}\text { MT > control (frontal, hippocampal, and cerebellar } \\
\text { region of the brain) }\end{array}$ \\
\hline & Park et al., 2016 & The reduction of agitation & Preferred music & 14 patients & Preferred music $>$ control \\
\hline & Sun and Chen, 2015 & EEG; GCS & Music Therapy (MT) & 40 patients & Music group > control group \\
\hline & Magee et al., 2016 & MATADOC & / & 21 patients & $\begin{array}{l}\text { MATADOC subscales two }=\text { MATADOC subscales } \\
\text { three }\end{array}$ \\
\hline & Magee et al., 2015 & $\begin{array}{l}\text { MATADOC; CRS-R; CNC; } \\
\text { PCC }\end{array}$ & / & $\begin{array}{l}4 \text { patients } \\
\text { (children) }\end{array}$ & MATADOC > others (auditory and visual) \\
\hline & $\begin{array}{l}\text { O'Kelly and Magee, } \\
2013\end{array}$ & MATADOC; SMART & / & 42 patients & $\begin{array}{l}\text { MATADOC > SMART (auditory and visual); } \\
\text { SMART > MATADOC (motor) }\end{array}$ \\
\hline
\end{tabular}

">" means that there is a better or more significant response to the corresponding stimulus or methods. "=" means that there is a equal response to the corresponding stimulus or methods. UWS, unresponsive wakefulness syndrome; MCS, minimally conscious state; CRS-R, Coma Recovery Scale-Revised; GCS, the Glasgow Coma Scale; CNC, the COMA/Near Coma Scale; SMART, The Sensory Modality Assessment and Rehabilitation Technique; MATADOC, Music therapy assessment tool for awareness in disorders of consciousness; PCC, The Pediatric Center Criteria for Diagnosing a Persistent Vegetative State; ERP, event related potentials; SCL, skin conductance level; EEG, Electroencephalogram; fMRI, functional magnetic resonance imaging; RMNS, relaxing music with nature sounds; CRM, classical relaxing music; AMT, active music therapy. 
as it determines the level of processing the patient can achieve with the stimulation from his/her environment, and a personalrelevant stimulus works better than an irrelevant stimulus, therefore calling a subject's name could be the best choice of the diagnosis of DOC patients. It must be noted that there is no consensus on how to clinically assess the localization to sound in patients recovering from coma.

\section{AUDITORY STIMULATION FOR PROGNOSIS}

"Calling one's name" has been incorporated into the latest guidelines for disorders of consciousness in the United States. Family members often call the patient's name during the nursing process and there is a term in psychology called the "cocktail party effect" (Wood and Cowan, 1995), which refers to the fact that if someone calls your name in a very noisy environment (such as a cocktail party), you will hear it first, indicating that the act of calling someone's name can enter consciousness before other auditory stimuli. This phenomenon also exists in patients with consciousness disorders, and can represent the most effective stimulus. Calling the patient's name has become a staple in the field of international consciousness disorder research and has been widely used in clinical practice. In addition, it has the significant advantage of eliciting some behavioral responses compared to the stimulation of other auditory channels such as bells (Naci and Owen, 2013).

As early as in Di et al. (2007) found out that when hearing a familiar voice calling their names, two patients experienced VS joint temporal lobe area in the brain (higher level of auditory processing area) activation, while other patients just showed activation in the primary auditory cortex. The two patients mentioned before regained consciousness after 3 months. Another research showed that in a passive condition, alpha desynchronization was observed during familiar voice and name stimuli in the right hemisphere (del Giudice et al., 2014). Working with a leading international team, patients were asked to imagine a scene during which they imagine a scene during an imaginary scene. The study found that the etiology of patients can further improve the accuracy of prognosis prediction. Traumatic VS patients with auditory cortical activation were more likely to recover consciousness $(92.3 \%)$. Non-traumatic VS patients without this activation were more likely to have a poor prognosis (85\%) (Wang et al., 2015).

According to EEG studies, hearing a subject's own name induces the positive component of event-related potential and beta power suppression (Tamura et al., 2016). SON as a novel feature in an MMN design can be utilized to increase the prognostic value of ERPs in comatose patients and to assess unconscious cognitive processes in uncommunicative patients (Fischer et al., 2008). And the presence of a novelty P3 in response to the subject's own first name presented as a novel stimulus has shown a good correlation with coma awakening (Morlet and Fischer, 2014).

Calling patients' names is not merely a kind of stimulant commonly used by family members, but also more likely to result in self-consciousness and social consciousness. It has been shown to have a prognostic effect, indicating an increased chance of recovery within 12 months (Giacino et al., 2018b).

\section{AUDITORY STIMULATION FOR TREATMENT MEASURE}

As proven by several studies, music is a useful auditory stimulation that plays a fundamental role in DOCs. Here, we will discuss its use in DOC therapy.

A fMRI study carried out by Okumura in 2014 (Magee et al., 2014) showed that the activation of bilateral STG (superior temporal gyri) in patients with MCS was different than in VS patients during three different tasks with three types of sounds, such as a baseline sound stimulation, an instrument sound stimulation and a music stimulation. The results indicated that, compared to meaningless sound, brain activation is easier to be observed during MS (Okumura et al., 2014). Another study on functional connectivity showed that, compared to generic music, the auditory network showed stronger functional connectivity in the left precentral gyrus and the left dorsolateral prefrontal cortex during the listening to the patient's preferred music, and the functional connectivity of the external network was also enhanced in the temporo-parietal junction (Heine et al., 2015). Perrin et al. proposed that the reason for the positive effects of preferred music on arousal and attention observed in DOC is that the music prompts the activation of two anticorrelated brain networks for internal and external engagement at the same time, unlike the usual pattern, and their theory explained the findings in other similar studies (Perrin et al., 2015).

Though evidence is still limited, neuroimaging studies have shown that music listening activates a list of bilateral networks related to attention, memory and sensory system (O'Kelly et al., 2013; Rollnik and Altenmuller, 2014), and given its ability to boost cognition in DOC, music is a useful tool. It potential role in the treatment of DOCs has been highlighted in recent years, and behavioral and physiological methods have been applied to verify its reliability (Raglio et al., 2014; Ribeiro et al., 2014). But only recently brain imaging methods like fMRI, PET, EEG have been introduced in the research about music therapy in DOCs. A study employing PET as a reliable measure to better understand the relationship between music therapy and neuroscience before, during and after music therapy (Steinhoff et al., 2015) scanned the metabolism of the brain three times with PET during resting state, first exposure to music therapy (MT), and last exposure to MT. The final result showed that in the three areas analyzed in this study, the frontal areas, the hippocampus and the cerebellum, patients in music therapy showed higher brain activity than the control group (Steinhoff et al., 2015). The same conclusion was carried out in three other EEG studies (O'Kelly et al., 2013; Sun and Chen, 2015; Park et al., 2016), one of which aimed at evaluating the effects of a preferred music intervention on the reduction of agitation in TBI patients, showing that patients in music therapy also had better behavioral or neurophysiological indexes than the control group, and that a significantly greater reduction in agitation was observed in the patients listening 
to the preferred music (Park et al., 2016). These results stated that music therapy can prompt the activation of related brain regions, promote the recovery of patients' behavior and improve the conscious state of DOCs (Okumura et al., 2014; Rollnik and Altenmuller, 2014; Heine et al., 2015; Perrin et al., 2015), and that personally relevant stimuli like preferred music are more effective. This is consistent with the conclusion drawn from the studies listed above (Cheng et al., 2013; Verger et al., 2014; Heine et al., 2015).

For its unique role as a personally relevant stimulus and the lack of sensitive assessment in auditory block in CRS-R, the "Music therapy assessment tool for awareness in disorders of consciousness "(MATADOC) has been developed as a more detailed auditory assessment tool (Magee et al., 2014) based on three subscales, the "Principal Subscale", the "Musical Parameter and Behavioral Response Type" and the third subscale, "Clinical Information to Inform Goal Setting and Clinical Care" (Magee et al., 2014). Only the "Principal Subscale" is a diagnosis tool, while the other two subscales are designed to guide treatment (Magee et al., 2016). MATADOC could serve as an effective tool for the pediatric population suffering from DOCs, given the lack of language and motor functions (Magee et al., 2015).

Though music is not as promising as calling the patient's name in diagnosis, as a well-worked auditory stimulation, its application in the treatment of DOCs has been widely shown to be useful, but more neurophysiology and behavioral support is also required to figure out the exact connection between music therapy and the recovery of consciousness.

\section{DISCUSSION}

As a kind of sensory stimulation, auditory stimulation can efficiently provide a good cognitive environment for patients suffering from acute brain injuries, helping patients recover and serve as a diagnostic tool or reference to judge patients' states of consciousness, and its role is increasingly known by the public in terms of treatment and diagnosis (O'Kelly et al., 2013; Rollnik and Altenmuller, 2014). As the strongest personalrelated stimulus, Calling patients' names can effectively activate the related brain regions, and the difference between MCS and VS can be seen through imaging techniques like fMRI or PET (the studies involved are listed above in this paper) (Perrin et al., 2006; Di et al., 2007; Qin et al., 2008; Cheng et al., 2013). fMRI studies assessing brain activation to the patients' names have reported the activation of self-related brain regions depending on the level of consciousness in patients recovering from coma (Di et al., 2007; Cheng et al., 2013) and compared to music, hearing names seem to be a more promising stimulation to boost cognition, as proven by the fact that cerebral activation was higher in patients stimulated by their own name, especially in the temporal lobe (Wu et al., 2018). As for music, it's more like a treatment. O'Kelly et al. integrate music stimulation with other sensory stimulations to make a music-based scale, the function of which is mainly guiding treatment (Magee et al., 2014, 2016), while some researches have shown that personal related stimulation provides a better cognition state (Wu et al., 2018), and, compared to preferred music, normal music has a weaker improvement in DOC.

But it is difficult to employ sound stimulation as a sufficient tool of diagnosis, prognosis and treatment. First, the choice of sound is very subjective. The definition of personal related stimulus is not so clear, making it difficult for doctors to choose the most suitable sound stimulation (Wu et al., 2018), although the name is now clinically considered to be one of the best sources of stimulation and the application of the name is extensive and effective in diagnosis and prognosis, but its role in the treatment is not as significant as music (Sun and Chen, 2015). The author speculates that this may be related to the simple pronunciation of the name, the single content, and the tone of the calling, volume, etc. Music is relatively rich in content and can be well controlled in volume. A varied source of stimulation may do well in improving the patient's state of mind, but how to choose the music is a challenge. At present, the choice of music is largely based on the patient's family's judgement and the popularity of the music, which increases the uncertainty of the treatment efficacy, as the diagnosis of children with mental disorders based on music shows. The second problem is in the diagnostic method. At present, the most credible method is the medical imaging. However, the operation is cumbersome. A diagnosis often takes a long time to prepare and analyze, and it costs more. This is detrimental to the accurate treatment of patients, and it is not the most appropriate choice for some patients. Third, given the number of samples and neuroanatomical evidence, the current sample number of studies is not high enough to promote auditory stimulation as an effective diagnostic tool. At present, the studies on the relationship between hearing and consciousness are mostly carried out on rats and non-patients under general anesthesia. Auditory consciousness has been well studied in humans, and auditory cortical neuron processing has also been well studied in animal models (Eagleman and MacIver, 2018). However, the latest experimental results show that there is no relationship between the activity of primary auditory cortex and the loss of conscious activity in rats under general anesthesia (Eagleman and MacIver, 2018), and the generation of consciousness is complex. The reason why auditory stimulation was chosen as an indicator is that some patients cannot show clinical behavior to the stimulation but their retention of consciousness can be observed in imaging. This part of the patient's cortex response to sound stimulation is similar to that of healthy people (Okumura et al., 2014). But the neuroanatomical basis of the connection of auditory cortex and consciousness generation has not yet been discovered. The activation of the auditory cortex cannot diagnose the patient's state of consciousness alone.

\section{CONCLUSION}

In conclusion, calling the patient's name is a better choice than music as an effective auditory stimulation, but music has its unique role in treatment. Auditory stimulation still cannot be 
an independent diagnostic tool, and its value in diagnosis needs to be matched with other sensory stimulation. The diagnosis of DOC requests multidimensional assessments. The relationship between auditory stimulation and consciousness is still unknown. Future studies need to be more precise, focusing on the connection between auditory stimulation and consciousness in neurology with a larger sample.

\section{AUTHOR CONTRIBUTIONS}

JZ, YY, and YL contributed to the conception and design of the study. JZ and YL organized the database and wrote the first draft

\section{REFERENCES}

Allen, J. S., Emmorey, K., Bruss, J., and Damasio, H. (2013). Neuroanatomical differences in visual, motor, and language cortices between congenitally deaf signers, hearing signers, and hearing non-signers. Front. Neuroanat. 7:26. doi: 10.3389/fnana.2013.00026

American Congress of Rehabilitation Medicine., Brain Injury-Interdisciplinary Special Interest Group, Disorders of Consciousness Task Force, Seel, R. T., Sherer, M., Whyte, J., Katz, D. I., et al. (2010). Assessment scales for disorders of consciousness: evidence-based recommendations for clinical practice and research. Arch. Phys. Med. Rehabil. 91, 1795-1813. doi: 10.1016/j.apmr.2010. 07.218

Bekinschtein, T., Leiguarda, R., Armony, J., Owen, A., Carpintiero, S., Niklison, J., et al. (2004). Emotion processing in the minimally conscious state. J. Neurol. Neurosurg. Psychiatry 75:788. doi: 10.1136/jnnp.2003.034876

Berlad, I., and Pratt, H. (1995). P300 in response to the subject's own name. Electroencephalogr. Clin. Neurophysiol. 96, 472-474. doi: 10.1016/01685597(95)00116-a

Cheng, L., Cortese, D., Monti, M. M., Wang, F., Riganello, F., Arcuri, F., et al. (2018). Do sensory stimulation programs have an impact on consciousness recovery? Front. Neurol. 9:826. doi: 10.3389/fneur.2018. 00826

Cheng, L., Gosseries, O., Ying, L., Hu, X., Yu, D., Gao, H., et al. (2013). Assessment of localisation to auditory stimulation in post-comatose states: use the patient's own name. BMC Neurol. 13:27. doi: 10.1186/1471-2377-13-27

Cook, C. J., Hwang, G., Mathis, J., Nair, V. A., Conant, L. L., Allen, L., et al. (2019). Effective connectivity within the default mode network in left temporal lobe epilepsy: findings from the epilepsy connectome project. Brain Connect. 9, 174-183. doi: 10.1089/brain.2018.0600

del Giudice, R., Lechinger, J., Wislowska, M., Heib, D. P., Hoedlmoser, K., and Schabus, M. (2014). Oscillatory brain responses to own names uttered by unfamiliar and familiar voices. Brain Res. 1591, 63-73. doi: 10.1016/j.brainres. 2014.09.074

Di, H. B., Yu, S. M., Weng, X. C., Laureys, S., Yu, D., Li, J. Q., et al. (2007). Cerebral response to patient's own name in the vegetative and minimally conscious states. Neurology 68, 895-899. doi: 10.1212/01.wnl.0000258544. 79024.d0

Eagleman, S. L., and MacIver, M. B. (2018). Can you hear me now? Information processing in primary auditory cortex at loss of consciousness. $\mathrm{Br}$. J. Anaesth. 121, 526-529. doi: 10.1016/j.bja.2018.06.008

Fischer, C., Dailler, F., and Morlet, D. (2008). Novelty P3 elicited by the subject's own name in comatose patients. Clin. Neurophysiol. 119, 2224-2230. doi: 10. 1016/j.clinph.2008.03.035

Gerrard, P., Zafonte, R., and Giacino, J. T. (2014). Coma recovery scale-revised: evidentiary support for hierarchical grading of level of consciousness. Arch. Phys. Med. Rehabil. 95, 2335-2341. doi: 10.1016/j.apmr.2014.06.018

Giacino, J. T., Ashwal, S., Childs, N., Cranford, R., Jennett, B., Katz, D. I., et al. (2002). The minimally conscious state: definition and diagnostic criteria. Neurology 58, 349-353. doi: 10.1212/wnl.58.3.349 of the manuscript. ZS, XM, and YR wrote the sections of the manuscript. All authors contributed to the manuscript revision and read and approved the submitted version.

\section{FUNDING}

This work was supported by the National Natural Science Foundation of China (Grants 81920108023 and 81471100), the Hangzhou Normal University (Grant 2018PYXML007), and the Zhejiang University student science and technology innovation project (Grant 2019R426061).

Giacino, J. T., Katz, D. I., Schiff, N. D., Whyte, J., Ashman, E. J., Ashwal, S., et al. (2018a). Comprehensive systematic review update summary: disorders of consciousness. Neurology 91, 461-470.

Giacino, J. T., Katz, D. I., Schiff, N. D., Whyte, J., Ashman, E. J., Ashwal, S., et al. (2018b). Practice guideline update recommendations summary: disorders of consciousness: report of the guideline development, dissemination, and implementation subcommittee of the American Academy of Neurology; the American Congress of Rehabilitation Medicine; and the National Institute on Disability, Independent Living, and Rehabilitation Research. Neurology 91, 450-460.

Gill-Thwaites, H. (1997). The sensory modality assessment rehabilitation technique-a tool for assessment and treatment of patients with severe brain injury in a vegetative state. Brain Inj. 11, 723-734. doi: 10.1080/ 026990597123098

Heine, L., Castro, M., Martial, C., Tillmann, B., Laureys, S., and Perrin, F. (2015). Exploration of functional connectivity during preferred music stimulation in patients with disorders of consciousness. Front. Psychol. 6:1704. doi: 10.3389/ fpsyg.2015.01704

Heine, L., Tillmann, B., Hauet, M., Juliat, A., Dubois, A., Laureys, S., et al. (2017). Effects of preference and sensory modality on behavioural reaction in patients with disorders of consciousness. Brain Inj. 31, 1307-1311. doi: 10.1080/ 02699052.2017.1306108

Kempny, A. M., James, L., Yelden, K., Duport, S., Farmer, S. F., Diane Playford, E., et al. (2018). Patients with a severe prolonged disorder of consciousness can show classical EEG responses to their own name compared with others' names. NeuroImage Clin. 19, 311-319. doi: 10.1016/j.nicl.2018.04.027

Laureys, S., Celesia, G. G., Cohadon, F., Lavrijsen, J., Leon-Carrion, J., Sannita, W. G., et al. (2010). Unresponsive wakefulness syndrome: a new name for the vegetative state or apallic syndrome. BMC Med. 8:68. doi: 10.1186/1741-701 5-8-68

Li, J., Shen, J., Liu, S., Chauvel, M., Yang, W., Mei, J., et al. (2018). Responses of patients with disorders of consciousness to habit stimulation: a quantitative EEG study. Neurosci. Bull. 34, 691-699. doi: 10.1007/s12264-018-0258-y

Luaute, J., Dubois, A., Heine, L., Guironnet, C., Juliat, A., Gaveau, V., et al. (2018). Electrodermal reactivity to emotional stimuli in healthy subjects and patients with disorders of consciousness. Ann. Phys. Rehabil. Med. 61, 401-406. doi: 10.1016/j.rehab.2018.04.007

Magee, W. L., Ghetti, C. M., and Moyer, A. (2015). Feasibility of the music therapy assessment tool for awareness in disorders of consciousness (MATADOC) for use with pediatric populations. Front. Psychol. 6:698. doi: 10.3389/fpsyg.2015. 00698

Magee, W. L., Siegert, R. J., Daveson, B. A., Lenton-Smith, G. S., and Taylor, M. (2014). Music therapy assessment tool for awareness in disorders of consciousness (MATADOC): standardisation of the principal subscale to assess awareness in patients with disorders of consciousness. Neuropsychol. Rehabil. 24, 101-124. doi: 10.1080/09602011.2013.844174

Magee, W. L., Siegert, R. J., Taylor, S. M., Daveson, B. A., and Lenton-Smith, G. (2016). Music therapy assessment tool for awareness in disorders of consciousness (MATADOC): reliability and validity of a measure to assess 
awareness in patients with disorders of consciousness. J. Music Ther. 53, 1-26. doi: $10.1093 /$ jmt/thv017

Morlet, D., and Fischer, C. (2014). MMN and novelty P3 in coma and other altered states of consciousness: a review. Brain Topogr. 27, 467-479. doi: 10.1007/ s10548-013-0335-5

Naci, L., and Owen, A. M. (2013). Making every word count for nonresponsive patients. JAMA Neurol. 70, 1235-1241.

O'Kelly, J., James, L., Palaniappan, R., Taborin, J., Fachner, J., and Magee, W. L. (2013). Neurophysiological and behavioral responses to music therapy in vegetative and minimally conscious States. Front. Hum. Neurosci. 7:884. doi: 10.3389/fnhum.2013.00884

O'Kelly, J., and Magee, W. L. (2013). The complementary role of music therapy in the detection of awareness in disorders of consciousness: an audit of concurrent SMART and MATADOC assessments. Neuropsychol. Rehabil. 23, 287-298. doi: 10.1080/09602011.2012.753395

Okumura, Y., Asano, Y., Takenaka, S., Fukuyama, S., Yonezawa, S., Kasuya, Y., et al. (2014). Brain activation by music in patients in a vegetative or minimally conscious state following diffuse brain injury. Brain Inj. 28, 944-950. doi: 10. 3109/02699052.2014.888477

Park, S., Williams, R. A., and Lee, D. (2016). Effect of preferred music on agitation after traumatic brain injury. West J. Nurs. Res. 38, 394-410. doi: 10.1177/ 0193945915593180

Perrin, F., Castro, M., Tillmann, B., and Luaute, J. (2015). Promoting the use of personally relevant stimuli for investigating patients with disorders of consciousness. Front. Psychol. 6:1102. doi: 10.3389/fpsyg.2015. 01102

Perrin, F., Schnakers, C., Schabus, M., Degueldre, C., Goldman, S., Bredart, S., et al. (2006). Brain response to one's own name in vegetative state, minimally conscious state, and locked-in syndrome. Arch. Neurol. 63, 562-569.

Qin, P., Di, H., Yan, X., Yu, S., Yu, D., Laureys, S., et al. (2008). Mismatch negativity to the patient's own name in chronic disorders of consciousness. Neurosci. Lett. 448, 24-28. doi: 10.1016/j.neulet.2008.10.029

Raglio, A., Guizzetti, G. B., Bolognesi, M., Antonaci, D., Granieri, E., Baiardi, P., et al. (2014). Active music therapy approach in disorders of consciousness: a controlled observational case series. J. Neurol. 261, 2460-2462. doi: 10.1007/ s00415-014-7543-0

Rappaport, M., Dougherty, A. M., and Kelting, L. (2006). Evaluation of coma and vegetative states. Arch. Phys. Med. Rehabil. 42, 355-361.

Ribeiro, A. S., Ramos, A., Bermejo, E., Casero, M. J., Corrales, M., and Grantham, S. (2014). Effects of different musical stimuli in vital signs and facial expressions in patients with cerebral damage: a pilot study. J. Neurosci. Nurs. 46, 117-124. doi: 10.1097/JNN.0000000000000037

Rollnik, J. D., and Altenmuller, E. (2014). Music in disorders of consciousness. Front. Neurosci. 8:190. doi: 10.3389/fnins.2014.00190

Shiel, A., Horn, S. A., Wilson, B. A., Watson, M. J., Campbell, M. J., and McLellan, D. L. (2000). The wessex head injury matrix (WHIM) main scale: a preliminary report on a scale to assess and monitor patient recovery after severe head injury. Clin. Rehabil. 14, 408-416. doi: 10.1191/0269215500cr326oa

Steinhoff, N., Heine, A. M., Vogl, J., Weiss, K., Aschraf, A., Hajek, P., et al. (2015). A pilot study into the effects of music therapy on different areas of the brain of individuals with unresponsive wakefulness syndrome. Front. Neurosci. 9:291. doi: 10.3389/fnins.2015.00291

Stokes, V., Gunn, S., Schouwenaars, K., and Badwan, D. (2018). Neurobehavioural assessment and diagnosis in disorders of consciousness: a preliminary study of the sensory tool to assess responsiveness (STAR). Neuropsychol. Rehabil. 28, 966-983. doi: 10.1080/09602011.2016.1214604

Sun, J., and Chen, W. (2015). Music therapy for coma patients: preliminary results. Eur. Rev. Med. Pharmacol. Sci. 19, 1209-1218.

Tamura, K., Mizuba, T., and Iramina, K. (2016). Hearing subject's own name induces the late positive component of event-related potential and beta power suppression. Brain Res. 1635, 130-142. doi: 10.1016/j.brainres.2016.01.032

Teasdale, G., and Jennett, B. (1972). Assessment of coma and impaired consciousness. A practical scale. Lancet 2, 81-84. doi: 10.1016/s0140-6736(74) 91639-0

Verger, J., Ruiz, S., Tillmann, B., Ben Romdhane, M., De Quelen, M., Castro, M., et al. (2014). [Beneficial effect of preferred music on cognitive functions in minimally conscious state patients]. Rev. Neurol. 170, 693-699. doi: 10.1016/ j.neurol.2014.06.005

Wang, F., Di, H., Hu, X., Jing, S., Thibaut, A., Di Perri, C., et al. (2015). Cerebral response to subject's own name showed high prognostic value in traumatic vegetative state. BMC Med. 13:83. doi: 10.1186/s12916-0150330-7

Wood, N., and Cowan, N. (1995). The cocktail party phenomenon revisited: how frequent are attention shifts to one's name in an irrelevant auditory channel? J. Exp. Psychol. Learn. Mem. Cogn. 21, 255-260. doi: 10.1037//0278-7393.21. 1.255

Wu, M., Bao, W. X., Zhang, J., Hu, Y. F., Gao, J., and Luo, B. Y. (2018). Effect of acoustic stimuli in patients with disorders of consciousness: a quantitative electroencephalography study. Neural Regen. Res. 13, 1900-1906. doi: 10.4103/ 1673-5374.238622

Conflict of Interest Statement: The authors declare that the research was conducted in the absence of any commercial or financial relationships that could be construed as a potential conflict of interest.

Copyright (c) 2019 Zhu, Yan, Zhou, Lin, Shen, Mou, Ren, Hu and Di. This is an open-access article distributed under the terms of the Creative Commons Attribution License (CC BY). The use, distribution or reproduction in other forums is permitted, provided the original author(s) and the copyright owner(s) are credited and that the original publication in this journal is cited, in accordance with accepted academic practice. No use, distribution or reproduction is permitted which does not comply with these terms. 